\title{
Appeals to Considerations
}

\section{DAVID HitchCOCK}

\author{
Department of Philosophy \\ McMaster University \\ 1280 Main Street West \\ Hamilton, $O N$ \\ Canada L8S $4 L 8$ \\ hitchckd@mcmaster.ca
}

\begin{abstract}
Wellman's "conduction" and Govier's "conductive arguments" are best described as appeals to considerations. The considerations cited are features of a subject of interest, and the conclusion is the attribution to it of a supervenient status like a classification, an evaluation, a prescription or an interpretation. The conclusion may follow either conclusively or non-conclusively or not at all. Weighing the pros and cons is only one way of judging whether the conclusion follows. Further, the move from information about the subject's cited features to the attribution of a supervenient status is often but one moment in a more complex process.
\end{abstract}

Résumé: Les arguments que Wellman désigne de «conduction » et que Govier désigne de «conductive arguments», sont mieux décrits comme des appels à des considérations. Les considérations citées sont caractéristiques d'un sujet d'intérêt, et la conclusion est l'attribution à ce sujet d'un statut «supervenient» comme une classification, une évaluation, une recommandation ou une interprétation. La conclusion peut s'ensuivre de façon soit concluante ou non concluante, ou pas du tout. Peser le pour et le contre n'est qu'une seule façon de juger si la conclusion s'ensuit. En outre, le raisonnement partir de l'information sur les caractéristiques citées du sujet à l'attribution d'un statut «supervenient» n'est souvent qu'un moment dans un processus plus complexe.

Keywords: Trudy Govier, Carl Wellman, conduction, conductive argument, conductive reasoning, considerations, criteria, pros and cons 


\section{David Hitchcock}

\section{Introduction}

In his Challenge and Response: Justification in Ethics, Carl Wellman (1971) distinguished what he called "conduction" from deduction and induction. "Conduction," he wrote,

can best be defined as that sort of reasoning in which 1) a conclusion about some individual case 2) is drawn nonconclusively 3 ) from one or more premises about the same case 4) without any appeal to other cases. (p. 52)

Trudy Govier has done more than any other person to publicize and develop Wellman's work on this form of reasoning. Since her brief review of Wellman's book (Govier 1979), she has written five articles about what she calls "conductive arguments" (1980, ${ }^{1} 1987 \mathrm{a}$, 1987b, 1999, 2011), and has included successively longer treatments of them in each of the seven editions of her textbook (1985, pp. 259-261; 1988, pp. 247-253; 1992, pp. 308-316; 1997, pp. 388408; 2001, pp. 392-412; 2005, pp. 393-415; 2010, pp. 352-377). From the fourth edition (1997) on, they have been the main subject of a separate chapter entitled "Conductive arguments and counterconsiderations." It is a safe guess that so far no other introductory textbook has devoted nearly as much attention to this type of argument.

In this article, I use Govier's comprehensive treatment of conductive arguments as a foil for developing what I take to be a more adequate approach to the analysis and evaluation of this sort of reasoning. My thinking owes much to the collection of essays on conductive argument (Blair and Johnson 2011) that emerged from a conference on the topic at the University of Windsor in 2010.

${ }^{1}$ Here, and in the rest of this article, citations whose author is unnamed are to Govier's publications listed in the references.

(c) David Hitchcock. Informal Logic, Vol. 33, No. 2 (2013), pp. 195-237. 


\section{Some examples}

It is important in theorizing about reasoning and argument to keep one's eye on real examples of the phenomenon one is theorizing about. By real examples, I mean either discursive thinking about some question at issue or communication of such thinking to others (interactively or not, with a view to persuasion or revelation or any other end). Real examples contrast with artificial examples invented by a textbook writer or scholar to illustrate a phenomenon. Artificial examples may be realistic, but we do not know whether they are until we compare them to real examples. The danger of theorizing on the basis of artificial examples is that we tailor our examples to our theoretical proclivities rather than tailoring our theorizing to the phenomenon we wish to understand. Allowance should be made, of course, for the possibility that real reasoning and argument has been shaped, for good or ill, by past theorizing to which the reasoner or arguer has been exposed.

To provide a focus for the present reflection, I shall be referring to what I take to be paradigm real cases of the phenomenon that Govier has done so much to help us understand. The cases are collected in the appendix to this article. They consist of five passages that Govier quotes in support of her claim that arguments of this sort occur (1999, pp. 160-166) and seven passages on the Web discovered in Google searches using the exact phrases "taking all these factors into account" and "therefore on balance." The passages give a sense of the range of types of judgments for which one can argue "conductively." Five are classifications, two are evaluations, two are recommendations, and there is one interpretation, one decision, and one causal claim.

The reader can find additional real examples in the two samples of arguments and inferences in (Hitchcock 2002, 2009), where they are classified under the labels "classification by criteria," "evaluation by criteria," "prescription by criteria," "pros-and-cons decision-making," and "pros-and-cons evaluation." In the sample taken from books in the library of a research-intensive university (Hitchcock 2002), more than a quarter of the arguments and infer- 


\section{David Hitchcock}

ences $(28 \%)$ were classified by these labels, with the most common form of argument by far (22\%) being evaluation by criteria. In the sample taken from phone calls to radio talk shows (Hitchcock 2009), 49\% of the arguments and inferences were classified by these labels, with the two most common types of reasoning in the sample being prescription by criteria $(33 \%)$ and evaluation by criteria $(13 \%)$. The high frequency indicates that so-called conductive reasoning is widespread. It therefore deserves theoretical attention.

The reader can also find what I take to be an extended example of such reasoning (65 pages long) in a recent decision by the Supreme Court of $\mathrm{Canada}^{2}$ on the question of whether a witness who wishes on religious grounds to keep her face covered with a niqab (i.e., a face veil) should be required to remove it during her testimony.

\section{Definition}

Govier understands conductive arguments as "arguments in which premises are put forward as separately and non-conclusively relevant to support a conclusion, against which negatively relevant considerations may also be acknowledged" (2011, p. 262). This definition differs from Wellman's in two respects. First, it drops the condition that the premises, counter-considerations if any, and conclusion concern an individual case, with no appeal to any other cases. Govier has always omitted this condition from her general descriptions of conductive arguments. She defends the omission on the ground that "it is easy to think of examples where separate facts are cited to nonconclusively support generalizations" (1987, p. 69). As her own example of this sort of argument, she gives the apparently invented and rather simplistic argument: "Blacks are equal to whites because they are as healthy as whites, they are biologically

\footnotetext{
${ }^{2}$ R. v. N.S., 2012 SCC 72 . The decision is available at: http://scc.lexum.org/decisia-scc-csc/scc-csc/scc-csc/en/12779/1/document.do (last accessed 201303 03)
}

(C) David Hitchcock. Informal Logic, Vol. 33, No. 2 (2013), pp. 195-237. 
very similar to whites, they are as intelligent as whites, and they share basic needs with whites" (1987, p. 69).

The second respect in which Govier's 2011 definition differs from Wellman's is in its shifting of the claimed non-conclusiveness of such arguments from the entire inference to the bearing of each supporting reason separately on the conclusion. The same shift occurs in the seventh edition of her textbook, where a footnote makes clear that an argument with several premises that each separately deductively entail the conclusion would not be conductive (2010, p. 376 , n. 2; cf. 1987 , p. 70 ). Govier notes $(2010$, p. 355) that an arguer who strongly acknowledges counter-considerations implicitly puts forward the conclusion as not conclusively established. Strong acknowledgement is admission that relevant considerations count against the conclusion, as opposed to weak acknowledgement that someone else might think, perhaps falsely, that there are such counter-considerations. The existence of relevant counterconsiderations does indeed imply that the premises collectively do not conclusively establish the conclusion, since conclusive support would deprive other features of the matter at issue of any negative relevance. As to conductive arguments without counterconsiderations, Govier has stated explicitly that a conductive argument "differs from a deductive argument because the factors cited do not entail, and are not put forward as being sufficient for, the conclusion cited" (1987, p. 66; cf. 1999, p. 155); in this context, "being sufficient for" should be understood in a strict sense of "being conclusive support for." In her textbook she has retained the condition that the premises do not collectively entail the conclusion (e.g. 1985 , p. $260 ; 1988$, p. $348 ; 1992$, p. 308; 1997, p. 388; 2001, p. $392 ; 2005$, p. $393 ; 2010$, p. 352 ) and has not retracted the condition that the factors cited are not put forward as entailing the conclusion.

Thus Wellman makes it a condition for reasoning to be conductive that the reasoner draws the conclusion non-conclusively (Wellman 1971, p. 52). And, similarly, Govier makes it a condition for an argument to be conductive that the arguer does not put forward the factors cited as sufficient for, i.e., conclusively support-

(C) David Hitchcock. Informal Logic, Vol. 33, No. 2 (2013), pp. 195-237. 


\section{David Hitchcock}

ing, the conclusion cited (Govier 1987, p. 66; 1999, p. 155). But, as has been argued in the case of attempts to classify reasoning and argument as deductive or inductive, such appeals to the intentions or claims or beliefs of reasoners and arguers are vacuous in many cases and are unnecessary for argument appraisal (Hitchcock 1980, 1981; Ennis 2001; Goddu 2001). As one can confirm for oneself by immediate retrospection, reasoners who draw a conclusion for themselves from information at their disposal are typically unaware of whether they are drawing it conclusively or non-conclusively. Reasoners just draw their conclusions, and it is only after that inferential act, if at all, that they determine whether their conclusion follows conclusively or non-conclusively. As for arguers, they sometimes claim a qualitative degree of support for their conclusion by qualifying it with terms like 'must' or 'probably' or 'presumably' or 'may.' But they do so in a minority of cases. For example, in a sample of 37 arguments or inferences made by callers to radio talk shows (Hitchcock 2009), 15 had a qualified conclusion, but eight of the 15 qualifiers were either 'I think' or 'I really think' or 'I believe,' apparent indicators of hesitation or modesty rather than of the claimed strength of the inferential support. (There were three indicators of conclusive support ['you've gotta,' 'it's not possible that,' 'they found out that'] and four indicators of what we might call conjectural support ['I guess,' 'my suggestion would be,' 'it would make sense that,' 'maybe'].) In a sample of 50 arguments or inferences in English-language books in the library of a research-intensive university (Hitchcock 2002), only five had a qualified conclusion, with three qualifiers ('must,' 'implies that,' 'obviously') indicating conclusive support and two indicating conjectural support ('suggests that,' 'seems to'). Without an explicit claim of the degree of inferential support, an argument analyst is merely guessing when attributing to the arguer a specific intention or belief about that degree. It makes sense to avoid such guessing, take the argument as stated, and simply determine how if at all the conclusion follows (Ennis 2001). Appraisal of the inference from premises to conclusion does not require attribution to the arguer of

(C) David Hitchcock. Informal Logic, Vol. 33, No. 2 (2013), pp. 195-237. 
a claim or intention or belief about the strength of inferential support.

In particular, in the five examples of Govier's in the appendix, only two qualify their conclusions, one with the phrase 'there is no doubt that' (presumably indicating claimed conclusive support) and the other with the phrase 'usually' (reflecting perhaps acknowledgement that in a minority of cases where parents deceive their children about Santa Claus either not all the cited factors obtain or there are other overriding factors). The seven other examples were selected by means of the qualification of their conclusion by the phrase 'taking all these factors into account' or the phrase 'therefore on balance,' but neither of these qualifiers implies that the inferential support is being presented as non-conclusive. Reasoners and arguers who think that they have taken all the relevant factors into account may well think that the position inferred follows conclusively from the reasons used to arrive at it in the light of any acknowledged counter-considerations.

If we drop the condition that conductive reasoning requires awareness that the premises do not support the conclusion conclusively and conductive argument requires a claim to that effect, we are left with the definition of conduction either as reasoning from one or more premises about an individual case to a conclusion about that same case (Wellman) or as argument in which premises are put forward as separately relevant to support a conclusion, possibly with acknowledgement of negatively relevant counterconsiderations (Govier). No appeal to possibly indiscernible and possibly non-existent intentions or beliefs is required to take an arguer to put forward premises as relevant or to acknowledge counter-considerations as negatively relevant. For the mere fact of using a statement as a reason for accepting a conclusion implicitly claims that the reason is relevant, i.e., useful in the context for showing that the conclusion is true or otherwise worthy of acceptance. Likewise, the mere fact of introducing a statement in the context of an argument with a concessive conjunction like 'even though' or 'although' or 'notwithstanding the fact that' amounts to a claim that the factor described in the statement is negatively relevant to

(C) David Hitchcock. Informal Logic, Vol. 33, No. 2 (2013), pp. 195-237. 


\section{David Hitchcock}

the conclusion. However, arguers do not always signal whether they take their supporting reasons to be separately relevant; further, if an indicator like 'moreover' or 'also' or 'besides' or 'further' introduces an additional supporting reason, it requires interpretation to determine whether the author intends the new reason to be sufficient on its own to support the conclusion (as is often the case, for example, in Aristotle's writings) or to combine with the previous reason to support the conclusion in a single inference. Further, some arguments that Govier wants to classify as conductive have just one premise, in which case the condition of putting forward each reason as separately relevant is not met. It must be admitted, on the other hand, that all 12 examples of conduction in the appendix indicate in one way or another that the reasons offered in support of the conclusion are separately relevant.

If we delete from Govier's definition the condition that the arguer puts forward each reason as separately relevant, we get a definition of a conductive argument as an argument in which one or more reasons are put forward as relevant to a conclusion, with the possibility that negative considerations may be acknowledged. This definition is much too broad, since it fits for example each of the following (invented) arguments, which on their face appear quite unlike any of Govier's examples:

(1) In each of the past 20 years, the maple tree in my garden has produced leaves in the spring. So it will produce leaves this coming spring. [One could split the single premise into 20, one for each of the 20 years, to get a multi-premise argument.]

(2) Every maple tree that I have observed in the winter in northern latitudes has shed its leaves. So probably all maple tress in northern latitudes shed their leaves in the autumn. [Again, one could split the single premise into a large number of premises, one for each maple tree observed.]

(C) David Hitchcock. Informal Logic, Vol. 33, No. 2 (2013), pp. 195-237. 
(3) Black oaks, bur oaks, cherrybark oaks, laurel oaks, white oaks, overcup oaks, post oaks and pin oaks are deciduous. So, even though live oaks are evergreen, probably most species of oaks are deciduous. [The premise is a conjunction with eight conjuncts, each of which could be expressed as a separate premise. And a counter-consideration is acknowledged.]

(4) Sunlight reaching the Earth is made up of all the colours of the rainbow. When sunlight reaches the Earth's atmosphere, the gases and particles in the air scatter it. The fact that blue light has shorter, smaller waves than other colours of light causes gases and particles in the air to scatter it more than those other colours. Therefore, the reason why a cloudless sky during the middle of the day is blue is that gases and particles in the air scatter the blue light in the sunlight reaching the Earth more than other colours of light.

(5) Susan is a few days late with her period. Her period usually comes at regular intervals. Susan has experienced slight spotting, but much less bleeding than she usually gets with her period. She has also experienced slight cramps, but again much less than the cramps that she usually gets with her period. She has also noticed a milky discharge from her vagina. She had intercourse within the last two weeks. So, although her breasts have not become tingly and her areola has not darkened, probably Sue is pregnant.

(6) Jupiter's moon Europa has water on it, just like Earth. Its surface is silicate rock, of a sort found on the surface of the Earth. So, even though it is much colder than Earth, there may be life on Europa.

Argument (1) is an inductive extrapolation from past behaviour to future behaviour, similar in structure and criteria of appraisal to extrapolations of a property from all observed individuals of some 


\section{David Hitchcock}

species or genus to another individual of the same kind. Argument

(2) is an inductive generalization from observed individuals of a kind to all individuals of that kind. Argument (3) is a qualitative statistical generalization from the distribution of a property in a sample of individuals of some kind (here individual species of a genus) to its distribution among all individuals of the kind. Argument (4) is an inference to a causal explanation from a series of causal processes involved in the production of an observed phenomenon. Argument (5) is mostly an argument from sign, which reasons from a collection of symptoms to a common cause that would explain them all; the premise that Sue had intercourse in the last two weeks provides a plausible causal pathway for the production of the apparent common cause of her symptoms. Argument (6) is an argument by analogy.

Each of the six arguments is of a type that has distinctive criteria of appraisal, unlike those one would be inclined to propose for conduction; further, they seem on their face unlike the paradigm cases of conductive arguments in the appendix. How can we narrow down Govier's truncated definition of conductive arguments so that it excludes arguments of these rather different types? Restoring the problematic conditions of presenting the reasons as separately relevant and jointly inconclusive will not help. For five of the six arguments just presented-all of them except argument (4) - can plausibly be interpreted as presenting their reasons as separately relevant and jointly inconclusive.

In dropping Wellman's condition that conductive reasoning be about an individual case, with no reference to other cases, Govier appears to have thrown out the baby with the bath-water. Even though the subject of conductive argument may be a general policy rather than an individual case, the examples that she cites have a common structure in which the premises and counterconsiderations if any mention features of a single subject of interest and the conclusion attributes a further property to that same subject. Her counter-example of a four-premise argument that blacks are equal to whites, for instance, has as a shared subject of interest the ordered pair <blacks, whites>; the conclusion attributes to this

(C) David Hitchcock. Informal Logic, Vol. 33, No. 2 (2013), pp. 195-237. 
ordered pair the property of being equal to on the basis of four features of the pair. The 12 examples in the appendix have as their subjects of interest (the topic shared by each premise and by the conclusion) the plot of Wuthering Heights, the sentence 'this exists' said of a sense-datum of which the speaker is directly aware at the time of utterance, the Santa lie, Trebbe Johnson's lifestyle, an annual conference scheduled for Atlantic City soon after Hurricane Sandy struck the New Jersey coast, voice recognition software, national risk registers, a resort hotel in the Yucatan Peninsula, a proposal for backloading in the European Union's emission trading scheme, two problematic spindle cell sarcomas, and a proposed option for international criminal health checks. Each argument cites features of the subject of interest that count for, and in some cases against, the conclusion drawn. Thus the abstract form of a conductive argument is as follows, where the 'even though' clause may be empty: $\left\langle x_{1}, \ldots, x_{\mathrm{m}}\right\rangle$ has features $F_{1}, \ldots, F_{\mathrm{n}}$; therefore, even though $<x_{1}, \ldots, x_{\mathrm{m}}>$ has features $H_{1}, \ldots, H_{\mathrm{k}},\left\langle x_{1}, \ldots, x_{\mathrm{m}}>\right.$ is $G$. (See Freeman 2011, p. 128.)

Adding to Govier's truncated definition the requirement that the argument have the just-mentioned abstract form will automatically exclude from the class of conductive arguments all but one of the six types illustrated by arguments (1) through (6): inductive extrapolations and generalizations, statistical generalizations, arguments from underlying cause-effect relationships to the causal explanation of some phenomenon, arguments by analogy. It does not rule out arguments from sign like argument (5). Nor does it rule out arguments from possession of a complex property to possession of one of its alleged constituents, as in the (invented) argument, "Jones is a bachelor, so Jones is unmarried."

What distinguishes conductive reasoning and argument from arguments from sign and arguments from complex properties to their simple constituents is that the conclusion of conductive reasoning or argument attributes a supervenient status to the subject of interest, on the basis of factors that the reasoner takes to count for or against its having that status. The reasoner takes the status to be constituted by a complex of types of considerations, and to be in-

(C) David Hitchcock. Informal Logic, Vol. 33, No. 2 (2013), pp. 195-237. 


\section{David Hitchcock}

capable of varying independently of them. Passage 9 in the appendix is typical: whether the resort hotel under review is worth going back to does not vary independently of its setting, the cleanliness of the beach, and the other factors mentioned by the reviewer-whose presence or absence, perhaps in combination with other unmentioned factors, she takes to be constitutive of whether a resort hotel is good enough to go back to. In contrast, arguments from sign are not arguments for some supervenient status based on allegedly relevant considerations and counter-considerations. They are arguments for some supposed cause, whose presence is in principle independently determinable, in example (5) above by a pregnancy test, and which is not prevented by conceptual or normative constraints from varying independently of the cited signs and symptoms (in the sense that two women could share the cited signs and symptoms even though one is pregnant and the other is not, and even though they do not differ with respect to any other sign or symptom of pregnancy). Similarly, marital status does not supervene on bachelorhood but is a definitional component of it. (Admittedly, a person's marital status does supervene on other facts about their history and cannot vary independently of such facts. So there can be conductive arguments that a person is unmarried, based on premises about the person's life history.)

Thus, we can define conductive reasonings and arguments as those in which a supervenient status is attributed to a subject of interest on the basis of one or more features of that subject, with possible acknowledgement of features that count against the attribution. The subject may be a class rather than a first-order entity, and it may be an ordered $n$-tuple (pair, triple, etc.) rather than an individual. The supervenient status will typically be evaluative, prescriptive, interpretive or classificatory.

Such reasoning can be deductively valid, in the broad sense that the meaning of its constituents rules out the possibility of true premises and a false conclusion. For some criteria of classification, evaluation, decision-making or interpretation are conclusive. For example, if one accepts the contemporary zoological definition of a reptile as an amniote vertebrate descended from the most recent

(C) David Hitchcock. Informal Logic, Vol. 33, No. 2 (2013), pp. 195-237. 
ancestor of living turtles, crocodilians and lizards, ${ }^{3}$ one will take the claim that birds are reptiles to follow deductively from the fact that birds are vertebrates, are suspended in a membrane in their embryonic stage, and are descended from the most recent ancestor of living turtles, crocodilians and lizards.

It also worth noting that introduction of a conclusion by the phrases "taking all these factors into account" or "therefore, on balance" does not necessarily signal conductive reasoning. Among the examples turned up in a search using the phrase "taking all these factors into account" was an argument predicting an effect on the basis of alleged causal factors. This piece of reasoning did not involve appeal to allegedly constitutive factors to support attribution of a supervenient status. Arguments of this sort, which reason from one or more causally relevant factors to a predicted effect, postulate a cumulative causal influence that is quite different from the cumulative contribution of features of a case to its interpretation, evaluation, classification, or policy decision. For one thing, with the passage of time it can become clear quite independently of any causally relevant factors whether the predicted effect occurs, whereas the correctness of an interpretation, evaluation, classification or policy decision cannot be judged independently of the sorts of considerations adduced in conductive reasoning to support it. For another thing, the causal relevance of a factor to a possible effect is established in a different way than the constitutive relevance of a factor to some supervenient status; in the former case one needs to appeal to empirically derived information about mechanisms of influence and underlying structural determinants, but in the latter case one needs to think in a more a priori fashion about what counts for or against the supervenient status in question. Yet another difference between the two types of reasoning is that assigning a supervenient status to a case on the basis of relevant and cumulative considerations often involves consideration of one or more rival supervenient statuses (other possible interpretations,

\footnotetext{
${ }^{3}$ Darren Naish, "What Is The Definiiton Of 'Reptile'?” Ask A Biologist (http://www.askabiologist.org.uk/answers/viewtopic.php?id=855 ; Accessed $20121206)$.
}

(C) David Hitchcock. Informal Logic, Vol. 33, No. 2 (2013), pp. 195-237. 


\section{David Hitchcock}

other possible policy decisions), whereas predicting an effect on the basis of causally relevant factors typically is more linear and less attuned to rival predictions.

Similarly with the phrase "therefore, on balance." Among the examples turned up in a search using this phrase was an argument that a positive test result for antibodies to HIV (the virus that causes AIDS) was "on balance" probably a false positive because of an inquirer's low antecedent risk of exposure to the virus. The "balancing" in this case involved a calculation using Bayes' theorem, that the posterior probability of a hypothesis (HIV infection in this case) given new evidence (the positive test result) is its prior probability (before the new evidence became available) times the ratio of the likelihood of the evidence given background knowledge if the hypothesis is true (the inquirer is infected) to its likelihood given just background knowledge; given a low prior probability, the posterior probability will be low even if a positive test result is more likely when a test subject has an HIV infection than when only background knowledge is taken into account. Calculations of this sort are quite different from judging the comparative contribution of positively relevant and negatively relevant factors to the assignment of some supervenient status.

Thus neither the abstract form ' $x$ has features $F_{1}, \ldots, F_{\text {n }}$; therefore, $x$ is $G$ ' nor indicator phrases like 'taking all these factors into account' and 'therefore on balance' distinguish conduction from other kinds of reasoning; the abstract form is a necessary but not sufficient condition for conduction, and the indicator phrases are suggestive but neither necessary nor sufficient.

\section{Name}

Govier has defended the use of the name 'conductive arguments' in preference to the names that others have given to such arguments: 'cumulation of consideration arguments,' 'balance of consideration arguments,' 'good reasons arguments' (2010, p. 353). To the name 'good reasons arguments' adopted by Kurt Baier (Baier 1958, p.

(C) David Hitchcock. Informal Logic, Vol. 33, No. 2 (2013), pp. 195-237. 
39), Govier objects that sometimes the reasons in arguments of this kind are not good, either because they are individually irrelevant to the conclusion or because they are collectively insufficient to support it $(2010$, p. 353$)$. One might also note that the name 'cumulation of consideration arguments' fits cases where more than one supporting reason is provided, but does not fit cases like passages 2 and 12 in the appendix, where there is only one supporting reason. The name 'balance of consideration arguments' fits only conductive arguments where counter-considerations are strongly acknowledged, and is thus inappropriate as a name for the whole class of conductive arguments. Names like 'pro and contra argumentation,' derived ultimately from the work of Arne Naess (1966), are misleading for the same reason, and also have the disadvantage of including cases like the consideration of arguments for and against the existence of God, which neither Govier nor Wellman would want to include in the class of conductive arguments. A name that picks out the most salient feature of the definition just developed is 'appeal to considerations' or 'appeal to criteria,' provided that one takes the plural of 'considerations' and 'criteria' to include the singular. 'Appeal to one or more considerations or criteria' gives the clearest sense of the type of reasoning and argument, but is wordy.

\section{Structure}

Govier declares that the support for the conclusion of a conductive argument is "always convergent" (2010, p. 352). She oscillates in her description of what convergent support amounts to between a characterization in terms of the way the author presents the argument and a characterization in terms of the substantive relationship of the individual reasons to the conclusion (p. 352; cf. her 1999, p. 156). On the first characterization, support is convergent if and only if the reasons are put forward as separately relevant to the conclusion. On the second characterization, support is convergent if and only if the reasons are actually separately relevant to the conclusion, in the sense that each of them counts separately for the 


\section{David Hitchcock}

conclusion: "If one or more premises were to be removed from the argument, the relevance to the conclusion of the remaining premises would be unaffected" (2010, p. 352). Since Govier allows that some conductive arguments may contain irrelevant premises that are falsely put forward as relevant, she ought to prefer the first characterization in terms of how the premises of a conductive argument are presented. However, as previously noted, it may be hard, or even impossible, to tell whether reasons offered as a basis for attributing a supervenient status are presented as separately relevant. The first passage in the appendix, for example, cites three features of the plot of Wuthering Heights in support of the claim that the entire plot has a vague incestuous aura without indicating in any way their separate relevance to the conclusion.

Through all seven editions of her textbook, Govier has represented conductive arguments diagrammatically with a separate line with an arrow at its end going from each premise or counterconsideration to the conclusion - a straight line from each premise and a wavy line from each counter-consideration. This diagram makes visual her view that authors of conductive arguments represent each premise as separately relevant to the conclusion and each strongly acknowledged counter-consideration as separately negatively relevant. But it fails to represent the "leading together" of the positively relevant and negatively relevant considerations which is the basis of applying the term 'conductive' to such arguments. At a conference on conductive arguments at the University of Windsor in 2010, Hansen (2011) and Jin (2011) among others raised questions about this failure, particularly in cases where counterconsiderations are acknowledged in an 'although' or 'even though' clause and there is an implicit so-called "on-balance premise" that the positive reasons outweigh the (strongly) acknowledged counter-considerations. To accommodate the failure, Govier proposes to add to her textbook diagram two lines of text between the converging arrows and the conclusion, the first with the on-balance premise and the second with the word 'therefore' (2011, p. 275).

Govier thus supposes that the author of a conductive argument makes one more inference claim than the sum of the number

(C) David Hitchcock. Informal Logic, Vol. 33, No. 2 (2013), pp. 195-237. 
of premises put forward as positively relevant and the number of strongly acknowledged counter-considerations. For each premise, the author claims independent positive relevance (helping to support the conclusion, quite independently of any other premise). For each strongly acknowledged counter-consideration, the author claims independent negative relevance (helping to reject the conclusion, quite independently of any other counter-consideration). And the author claims that the conclusion follows, perhaps defeasibly rather than conclusively, from the stated premises, even when one takes the strongly acknowledged counter-considerations into account. Thus, if the argument has three premises and acknowledges two counter-considerations, the author makes six inference claims: three of positive relevance for each of the three premises, two of negative relevance for each of the two counterconsiderations, and one of adequacy of support for the three premises as a group even when one takes into consideration the strongly acknowledged counter-considerations.

Despite its proliferation of targets for evaluation, this analysis seems to have much to be said for it. In order to appraise thoroughly an attribution of a supervenient status to a subject of interest on the basis of one or more of its alleged features, we need to determine whether each feature has any bearing on the supervenient status, and if it does whether the subject of interest really has the feature it is stated to have. Only after this initial check on the independent relevance of each feature cited, and on the acceptability of each claim that the subject of interest has that feature, can one determine whether the acceptable and independently relevant features on balance provide sufficient support for attributing the supervenient status.

\section{Scope}

What kinds of judgments can be supported by conductive arguments? From the beginning (1979, p. 12), Govier has emphasized 


\section{David Hitchcock}

the wide variety of judgments for which people argue conductively, not just:

particular moral judgments about individual cases (on which Wellman focused)

but also judgments of the following types:

aesthetic judgments, such as the judgment that a particular book is not a good one (1979, p. 12-an invented example taken from Wellman)

interpretive judgments, such as the judgment that Emily Bronte casts a vague incestuous aura over the entire plot of Wuthering Heights (1987, p. 71; repeated in 1999, p. 165-an actual example taken from a scholarly article on the incest theme in Wuthering Heights)

classificatory judgments, such as the judgment that Hume is not a sceptic (1979, p. 12; repeated in 1987, p.68 - an example invented by Govier, but in my judgment a realistic one) or the judgment that the Santa Claus story told to children is not a deeper truth but usually a white lie (1999, pp. 160-161-two real examples)

evaluative judgments about particular cases, such as the judgment that one's lifestyle is not environmentally pure (1999, pp. 161-162 - a real example)

judgments about philosophical concepts, such as the judgment that the sense-datum corresponding to the observed surface of an object either is usually not identical with that surface or usually lacks the qualities it is sensed as having (1987, p. 72; repeated in 1999, p. 163 - an argument put forward by John Wisdom) or the judgment that the sentence 'this exists' has meaning when the word 'this' is used of something with which we are

(C) David Hitchcock. Informal Logic, Vol. 33, No. 2 (2013), pp. 195-237. 
immediately acquainted at the time the sentence is uttered (1987, p. 72 - a real example put forward by G.E. Moore)

policy recommendations, such as the judgment that assisted euthanasia should not be legalized (1970, p. 3-a rather simplistic example invented by Govier) or the judgment that voluntary euthanasia should be a legal option for the terminally ill patient (1985, p. 261; 1988, p. 249; 1992, pp. 310-311; 1997, p. 393; 2001 , p. 397 ; 2005, p. 398 ; 2010, p. 360 - a somewhat less simplistic example, also invented by Govier, and discussed by her with increasing detail in successive editions of her textbook) or the judgment that tailoring sentences of convicted criminals to the particular facts of each case is highly impractical (1999, p. 164-a real example)

judgments that a hypothesis or theory under consideration is the best available explanation of a given set of facts (2010, p. 354; 2011, p. 263)

judgments about general causal relationships, such as the judgment that rape is not due to natural psychological impulses (1999, p. 162 - a real example) or the judgment that solving the problems of humanity requires not just application of the physical and biological sciences but also vast changes in human behaviour (1999, p. 163 - a real example, put forward by B.F. Skinner) or the judgment that punishment will make the criminal more morally sensitive (1999, p. 165 - a real example) or the judgment that the main beneficiaries of programs to combat global warming will be the developing countries (1999 p. 166a real example)

economic forecasts, such as the judgment that America has turned the corner on the depression of the last few years (1979, p. 12; repeated in 1987, p. 71 - an invented example taken from Scriven) 


\section{David Hitchcock}

Since causal relationships and future economic performance are not supervenient statuses, the definition proposed in this article of conductive arguments as appeals to considerations or criteria in support of a supervenient status would exclude the last two groups of arguments from the class of conductive arguments.

What about the process leading up to the construction of a conductive argument? Govier occasionally acknowledges (e.g., at 1979 , p. 14) that the utterance or inscription of a conductive argument may be the result of a prior process that includes things like sifting through evidence and trying to determine what is relevant. But she regards this process as a matter of reasoning rather than argument, presumably on the basis that it involves intra-personal thinking rather than inter-personal communication. She does not mention the possibility that the preliminary process may also involve inter-personal communication. Nor does she discuss the possibilities of inter-personal communication in the critical reaction and response to a conductive argument, as might occur for example when a judge writes a dissenting opinion in response to a conductive argument of the majority in a legal case. In her response to the papers at the 2010 symposium, she explains her reticence as due to a focus on brief arguments on such matters as whether to rent an apartment or hire one babysitter rather than another (2011, p. 266). She acknowledges there that on substantial public issues such as capital punishment or abortion the considerations in a conductive argument tend to be the result of prior debate and argumentation, and "there is a certain dynamism" (2011, p. 266) in which backand-forth discussion and recognition of counter-considerations may lead one to qualify an initial position. She does not however address the arguments of Harald Wohlrapp (Wohlrapp 2008a, 2008b, 2011) that her conductive argument scheme developed from Wellman's ideas is "a misleading model for the analysis of pro- and contra- argumentation" (Wohlrapp 2011, p. 210).

(C) David Hitchcock. Informal Logic, Vol. 33, No. 2 (2013), pp. 195-237. 


\section{Evaluation}

Govier's analysis of the structure of conductive arguments leads naturally to her position on how they should be evaluated. She sets out "the questions to be asked in evaluating conductive arguments" (1999, p. 169) quite succinctly in The Philosophy of Argument:

1. Are the premises rationally acceptable?

2. Is each premise, considered by itself, relevant to the conclusion?

3. How strong a reason does each relevant premise provide for the conclusion?

4. Considering all the supporting premises together, how strong is the support provided for the conclusion?

5. What are counter-considerations (strongly acknowledged by the arguer) that count against the conclusion?

6. What are the counter-considerations put forward by the evaluator or critic that count against the conclusion?

7. How strong is each of these counter-considerations as a reason against the conclusion?

8. How strongly do the counter-considerations, taken together, count against the conclusion?

9. Taking into account the deliberations at stages (4) and $(7)^{4}$, how much support overall, or on balance, is provided for the conclusion by the premises? (1999, p. 170)

The judgment that a conductive argument is cogent, she claims, implies that on balance the pros outweigh the cons to a sufficient degree that there are good grounds for the conclusion. The sufficiency here must be sufficiency in a weak sense compatible with non-entailment of the conclusion by the premises.

A similar but more concise list, in the form of instructions rather than questions, and including the conditions for summative judgments of cogency or non-cogency, appears in the second (1988) through the seventh (2010) editions of her textbook:

4 '(7)' here looks like a misprint for '(8)'.

(C) David Hitchcock. Informal Logic, Vol. 33, No. 2 (2013), pp. 195-237. 


\section{David Hitchcock}

1. Determine whether the premises offered to support the conclusion are acceptable.

2. Determine whether the premises offered to support the conclusion are positively relevant to it, and assess the strength of the reasons. [italicized words added from the fourth (1997) edition on-DH]

3. Determine whether any counterconsiderations acknowledged by the arguer are negatively relevant to the conclusion.

4. Think what additional considerations, not acknowledged by the arguer, are negatively relevant to the conclusion.

5. Reflect on whether the premises, taken together, outweigh the counterconsiderations, taken together, and make a judgment. Try to articulate good reasons for that judgment.

6. If you judge that the premises do outweigh the counterconsiderations, you have judged that the $(\mathrm{R})$ and $(\mathrm{G})$ conditions are satisfied. Provided that (A) is also satisfied, you deem the argument cogent. Otherwise, you deem it not to be cogent. (1988, pp. 249-250; 1992, pp. $311-312$; 1997, p. 397; 2001, pp. 401-402; 2005, p. 405; 2010, pp. 365-366)

This approach to evaluating a conductive argument is highly atomistic. It requires (explicitly in the 1999 list of questions, implicitly in the textbook list of instructions) separate judgments, using at least a rough cardinal measure, of the strength of support provided by each (rationally acceptable) premise, the strength of support provided by those premises collectively, the strength of opposition provided by each counter-consideration, the strength of opposition provided by the counter-considerations collectively, the difference between the collective strength of support from the premises and the collective strength of support provided by the counter-considerations, and the degree of support that is sufficient to provide good grounds for the conclusion. Evaluation of a conductive argument with three supporting premises, one strongly acknowledged counter-consideration and one unacknowledged counter-consideration identified by the evaluator, would require

(C) David Hitchcock. Informal Logic, Vol. 33, No. 2 (2013), pp. 195-237. 
nine distinct quantitative judgments, each presumably fallible or even necessarily subjective, with a concomitantly high risk of an error of judgment about the cogency of the argument. (Parenthetically, it should be noted that Govier has omitted one relevant evaluative question, namely, whether it is rational to accept that each of the strongly acknowledged counter-considerations in fact obtains.)

Further, and more significantly, Govier's approach to evaluating conductive arguments is exclusively product-oriented, i.e., oriented to the premise-conclusion structure of the finished argument to be evaluated. It makes no allowance for a discursive process, either by a single evaluator or in back-and-forth discussion, in which one considers modifying the way the question at issue is framed, the criteria or considerations that are deemed relevant, and the priority to be given to one factor in relation to another. This sort of process, to whose understanding significant contributions have been made by Harald Wohlrapp (2008a, 2008b, 2011) and by Sharon Bailin and Mark Battersby (Bailin and Battersby 2010, Bailin and Battersby 2011), and of which Fred Kauffeld has given a fine analysis in his brief case study of the debates in 1787 and 1788 over ratification of the United States Constitution (Kauffeld 2011), is particularly salient in the discussion of public policy issues to which Govier wishes to extend Wellman's framework.

In all seven editions of her textbook, Govier explains how one is to appraise a conductive argument with reference to an apparently invented example of an argument that voluntary euthanasia should be a legal option for the terminally ill patient:

(1) Voluntary euthanasia, in which a terminally ill patient consciously chooses to die, should be made legal. (2) Responsible adult people should be able to choose whether to live or die. Also, (3) voluntary euthanasia would save many patients from unbearable pain. (4) It would cut social costs. (5) It would save relatives the agony of watching people they love die an intolerable and undignified death. Even though (6) there is some danger of abuse, and despite the fact that (7) we do not know for certain that a cure for the patient's disease will not be found, (1) voluntary euthanasia

(C) David Hitchcock. Informal Logic, Vol. 33, No. 2 (2013), pp. 195-237. 


\section{David Hitchcock}

should be a legal option for the terminally ill patient. (1985, p. $261 ; 1988$, p. $249 ; 1992$, pp. $310-311 ; 1997$, p. $393 ; 2001$, p. $397 ; 2005$, p. $398 ; 2010$, p. 360$)$

The choice of example is unfortunate. It is a bare-bones and simplified, even simplistic, argument on a major sensitive and controversial matter of public policy. As such, it has no chance of being a cogent, i.e., compelling, argument. If this argument were the whole of an undergraduate student's essay on the issue, it would get a very low grade from any conscientious and capable marker. If it were the whole statement of a witness appearing before a legislative committee holding hearings on the proposed legislation, the committee members would pepper the witness with questions. It is not surprising that, in his extensive critique of Govier's weightand-sum approach to evaluating pro- and contra- discussion, Wohlrapp (2008a, pp. 320-334; 2008b, pp. 5-23) finds much to object to in her treatment of this example. Nevertheless, it serves as a starting-point for his own approach of applying the concept of frames to a dynamic discussion of issues on which there is pro- and contraargumentation.

We can extract from Govier's application of her atomistic and product-oriented evaluative procedure to her sample argument (2010, pp. 361-363) substantive guidelines for its application to other cases. She takes the relevance of a particular consideration to consist in a general principle that, other things being equal, if the consideration obtains, then the inferred status belongs to the subject at issue. For example, the relevance of cutting social costs-(4) in the passage quoted above - to the desirability of legalizing voluntary euthanasia (1) consists in the principle that, other things being equal, anything that cuts social costs should be legalized. A consideration should thus be deemed irrelevant if its corresponding general principle is rejected. A similar test can be applied to determine the negative relevance or irrelevance of any counter-considerations, whether acknowledged by the arguer or entertained by the evaluator.

As a basis for evaluating informally the strength of a reason judged relevant, Govier proposes the consideration of the range of

(C) David Hitchcock. Informal Logic, Vol. 33, No. 2 (2013), pp. 195-237. 
exceptions covered by the ceteris paribus clause. Although she rightly judges it to be impossible to list all the other things that would have to be equal in the case of the social costs consideration, she takes that range to be wide, excluding for example cost-cutting that deprives people of needed services, is cruel, contravenes recognized human rights, or sacrifices something valuable. Hence, she concludes, cutting social costs is a comparatively weak reason for legalizing voluntary euthanasia. Without going through the specifics, she reports her conclusion from applying this informal procedure for evaluating the strength of a reason that the right of responsible adults to choose whether to live or die (2) is also a comparatively weak reason for legalizing voluntary euthanasia, but that saving many patients from unbearable pain (3) and saving relatives the agony of watching people they love die an intolerable and undignified death (5) are comparatively strong reasons.

Govier does not go through the analogous procedure for evaluating the strength of the acknowledged counterconsiderations. One can conjecture that the strength of the danger of abuse (6) as a reason against voluntary euthanasia would depend according to Govier's procedure on the probable frequency of cases of abuse and the seriousness of the harm suffered in each such case; in other words, the counter-consideration would need to be fleshed out before we could judge the range of exceptional circumstances excluded by the ceteris paribus clause in the principle that, other things being equal, a practice with a risk of abuse should not be legalized. If we specify that the danger is a non-negligible frequency of people being put to death against their will, the range of exceptions would presumably be narrow, and the counterconsideration thus a comparatively strong one. As to the counterconsideration (7) that we do not know for certain that a cure for the patient's disease will not be found, here too more information is needed about how probable it is, given the available evidence, that a cure will be found before the terminally ill person dies from their illness.

In fact, the danger of abuse and the possibility that a cure for a terminal illness will be found would ordinarily be taken as rea-

(C) David Hitchcock. Informal Logic, Vol. 33, No. 2 (2013), pp. 195-237. 


\section{David Hitchcock}

sons for qualifying a proposal to legalize voluntary euthanasia, rather than as factors to be weighed in the balance against the reasons favouring legalization. For example, if one reads the Oregon Death with Dignity Act (Oregon 2011), one finds an elaborate set of conditions: who may initiate a request for life-ending medication and under what circumstances, the form of the written request, the responsibilities of the attending physician, confirmation by a second physician, possible referral of the patient for counselling, informed decision to receive the prescription, recommendation of family notification, repetition by the patient of the request, right of the patient to rescind the request, minimal time intervals between stages of the process, required documentation in the medical record, acceptable proofs of state residency, reporting requirements, effect of a request for life-ending medication on the construction of various legal documents (wills, contracts, statutes, insurance and annuity policies), prohibition of active euthanasia, immunities, liabilities, claims by governmental entities for costs incurred. It is obvious from reading the statute that it is the product of considerable backand-forth discussion, with much attention to detail (including hypothetical scenarios, objections from opponents of the legislation before it was enacted, points raised in submissions from professional organizations and business groups, and the like). Enacting legislation on helping a terminally ill person to end their own life is and ought to be a much more complex matter than noting relevant supporting reasons for a proposed statute, acknowledging negatively relevant counter-considerations, summing up the total strength on each side, and determining whether the total strength of the supporting reasons is sufficiently greater than the total strength of the counter-considerations to constitute grounds for passage of the bill. Similarly for other controversial issues of public policy.

In her sketch of how to appraise the argument for legalizing voluntary euthanasia for terminally ill patients, Govier laudably notes that there may be unacknowledged counter-considerations to the conclusion, such as compromising the primary role of physicians as healers and savers of lives and the possible inability of people undergoing severe pain to make rational decisions about

(C) David Hitchcock. Informal Logic, Vol. 33, No. 2 (2013), pp. 195-237. 
their lives. She does not mention a counter-consideration that is often overlooked in discussions of legalizing voluntary euthanasia or assisted suicide: the systemic effects of such legalization on socially accepted norms for decision-making by terminally ill patients.

Govier makes no attempt with this example to take the final steps of her recommended appraisal procedure: summing up the total strength of the stated reasons, summing up the total strength of the acknowledged and unacknowledged counter-considerations, calculating the difference, determining whether the difference (if it is positive) is big enough that the premises provide sufficient grounds for accepting the conclusion, even in the light of the counter-considerations. It is hard to imagine what the application of these final steps to her example would look like. The difficulty of imagining it casts doubt on the applicability of her proposed method of evaluation. A convincing way to show that it is applicable would be to actually apply it to a real (i.e., not artificial) appeal to considerations in support of a supervenient status. And a convincing way to test its reliability (i.e., its tendency to lead to the same result when applied on different occasions to the same argument) would be to measure its inter-rater reliability when applied by different trained evaluators to the same set of arguments.

In the most recent four editions of her textbook, Govier discusses the appraisal of one other conductive argument, generated from a real controversy over whether a university should block its students from using a university-provided account to access "extraordinarily explicit and brutal visual materials about bondage, bestiality, and sexual violence" available on the Internet (1997, pp. 396-397; 2001, pp. 400-401; 2005, pp. 402-404; 2010, pp. 363365). She uses this example to warn against "tunnel vision," where one takes one relevant consideration (in this example that blocking student access would be a kind of censorship) as decisive, thus dismissing out of hand as irrelevant other factors in the situation (making university resources unavailable for academic work, making the university vulnerable to hostile external criticism, giving the impression that the university approved this material by making

(C) David Hitchcock. Informal Logic, Vol. 33, No. 2 (2013), pp. 195-237. 


\section{David Hitchcock}

it available, intimidating women students if computers are left on showing pornographic material, possibly causing students to commit copycat offences). She points out quite rightly that taking the consideration that blocking such student access would be censorship as decisively settling the issue involves treating the argument as implicitly deductively valid, but that the implicit premise required for such deductive validity (that all censorship is wrong) is not worthy of acceptance. Further, once the implicit premise and the conclusion are appropriately qualified by a ceteris paribus clause, the considerations on the other side become relevant. Govier does not apply her appraisal procedure to an argument for or against blocking student access using university resources to pornographic material. She contents herself with remarking:

There is no simple recipe for arriving at a definite answer in contexts like these. Decisions must emerge from our judgment about the strength of the reasons put forward, assessed in the light of counterconsiderations. To reflect on pros and cons requires good judgment, which you have to supply for yourself. (2010, p. 365; cf. 1997, p. 397; 2001, p. 401; 2005, p. 404)

Govier's procedure for evaluating appeals to considerations has become more ramified and sophisticated in successive editions of her textbook, and is arguably the most thorough such procedure in print. It is more generally applicable, for example, than Benjamin Franklin's rather similar "moral and prudential algebra," described in a letter to Joseph Priestley in 1772, of putting down in two lists all the pros and cons relating to some measure, striking out reasons on each side that seem of equal weight, finding where the balance then lies, and making a determination once some time for further consideration elapses during which no new important reason pro or con occurs to him (Franklin 1956). But there is much to object to, with respect to both inclusions and omissions, in her appraisal procedure. Considering these objections and accommodating them can take us in the direction of a more adequate procedure.

(C) David Hitchcock. Informal Logic, Vol. 33, No. 2 (2013), pp. 195-237. 
An obvious objection is scepticism about our ability to measure the strength of each supporting reason and each counterconsideration. Govier herself remarks: "We cannot literally measure, or quantify, the strength or merits of the various premises against counterconsiderations" (1997, p. 392; 2001, p. 396; 2005, p. $397 ; 2010$, p. 356). A detailed attempt to unpack the metaphor of the pros "outweighing" the cons has been made by Pinto (2011). He reports being unpersuaded by attempts like that of John Pollock $(1995,2002)$ to assign real cardinal numbers to the strength of any argument or inference. Instead, Pinto assumes that "in most cases the best we can hope for is to make judgments about the comparative force or strength of individual considerations or sets of considerations" (Pinto 2011, p. 115; italics in original). Importantly, such comparative judgments, with respect to the set of supporting reasons and the set of counter-considerations, are enough to determine whether the supporting reasons are sufficient, in the light of acknowledged and unacknowledged counter-considerations, to justify acceptance of the conclusion. We don't need cardinal measures, just ordinal comparisons, perhaps with some rough sense of how much more weighty one consideration or set of considerations is than another. Further, Pinto has a convincing argument against Govier's attempt to assign a rough cardinal measure to a consideration on the basis of the kinds of factors that constitute exceptions to a ceteris paribus generalization and the frequency with which those kinds of factors occur. Determining whether a kind of factor is an exception to a ceteris paribus generalization, he points out (Pinto 2011, p. 117), requires ability to compare the strength of arguments licensed by that generalization to other arguments. Pinto argues that the strength of a consideration is a function of the risk taken in relying on it and its weight, the weight in turn being a function of the importance of the feature on which the consideration turns and the degree to which that feature is present. He sketches as a basis for further investigation an approach to working out the relative importance of criteria for the application of predicates with a normative dimension (i.e., what this article has earlier referred to as evaluative and prescriptive predicates) and of criteria 


\section{David Hitchcock}

for the application of purely descriptive predicates with open texture (i.e., what this article has earlier referred to as classificatory and interpretive predicates). He then works out principles for estimating the comparative strength of a single pro consideration and a single contra consideration on the basis of judgments of the relative importance of the two features on which the two considerations turn (based on whether we prefer a situation with one feature to a situation with the other "just a bit," "a fair amount" or "to a great extent"), the relative weight of the two considerations (determined by whether, other things being equal, we prefer a situation with one feature present to the degree it is present in the one consideration to a situation with the other feature present to the degree it is present in the other consideration "just a bit," "a fair amount" or "to a great extent"), and the degree of risk incurred in relying on each consideration (high, medium, low or nil). He points the way towards developing principles for more complicated comparisons of a set of pro considerations to a set of con considerations. Pinto's account appears to provide a way towards cashing out the metaphor of the pros "outweighing" the cons. But it is very abstract and, as he himself admits, not fully developed. More needs to be done to develop it and apply it to some real examples.

Quantitative comparisons, whether cardinal or ordinal, may however be the last resort in evaluating appeals to considerations. Kauffeld (2011) has pointed out other ways of ranking considerations that were used in the debates on the ratification of the United States constitution in 1787 and 1788. The Anti-Federalists who opposed its ratification raised a number of objections, each of which they took to be an overriding counter-consideration.The Federalist response that the merits of the constitution outweighed these defects proved unpersuasive, because it failed to take the AntiFederalist objections into account. Three Federalists writing under the pseudonym Publius then reframed the issues under consideration. The issue was not whether a power given to the national government was dangerous, they maintained, but whether the power was necessary and, if necessary, whether adequate safeguards had been included to protect against its abuse. This recasting of the is-

(C) David Hitchcock. Informal Logic, Vol. 33, No. 2 (2013), pp. 195-237. 
sue raised by each of the Anti-Federalists' counter-considerations enabled the two sides to meet on common ground. Kauffeld infers from this example that assigning weights to the various considerations and weighing them

seems to be one of several ways in which we manage pro and contra conductive arguments in attempting to reach a well reasoned conclusion. More basic reasoning/argument strategies involve ranking considerations and taking opposing considerations into account. But weight seems to be only one of several ways in which considerations can be ranked. (Kauffeld 2011, p. 166)

A rather different approach to evaluating appeals to considerations is taken by Freeman (2011), who applies his version of the Toulmin model to developing a set of "critical questions" for such arguments. Allen (2011) tests Freeman's proposal with reference to conductive argument used by two justices of the Supreme Court of Canada in support of conflicting judgments as to whether the Canadian Criminal Code statute prohibiting hate speech is consistent with the Charter of Rights and Freedoms that is part of Canada's constitution. He notes that the methodology used by the two justices does not lead them to follow the procedure Freeman recommends, of framing generalizing warrants and considering whether proper backing is available for them. Rather, it involves attention to the particularities of the case under review and judgments of reasonableness and of the values invoked in the light of those particularities. Allen concedes that, although the methodology used by the Supreme Court in such cases does not conform to Freeman's proposed method of appraising conductive arguments, an external evaluator might take Freeman's position. It may be, however, that the force of attention to the peculiarities of a case is to make the implicit warrant more specific. In that case, the judges' methodology may be consistent with Freeman's approach.

Beyond the appraisal of appeals to considerations in a static argument lies the whole process of developing and reworking the argument. It is this process on which Wohlrapp (2008a, 2008b,

(C) David Hitchcock. Informal Logic, Vol. 33, No. 2 (2013), pp. 195-237. 


\section{David Hitchcock}

2011) and Bailin and Battersby $(2010,2011)$ have many significant proposals. Considerations of space and time unfortunately do not permit discussion of their proposals in the present article.

\section{Summary}

I have argued that there is indeed a distinct form of reasoning of the sort Wellman and Govier describe, but that both the label 'conduction' and the common metaphor of weighing up the pros and cons are misleading. The form of reasoning is better described as an appeal to considerations (or to criteria). The considerations cited are features of a subject of interest, and the conclusion drawn from them is the attribution of some supervenient status to that subject, such as a classification, an evaluation, a prescription or an interpretation. The conclusion of such reasoning may follow either "conclusively" from its premises or non-conclusively or not at all. Weighing the pros and cons, however construed, is only one way of judging whether the conclusion follows, and perhaps only a last resort in making such judgments. Further, the move from information about the subject's cited features to the attribution of a supervenient status is often but one moment in a more complex process, a move that is typically preceded by other reasoning moves and may be followed by still others. In a thorough discussion of the supervenient status of such a subject, the relevant considerations and counter-considerations would ideally be integrated in such a way as to take the sting out of the counter-considerations.

\section{References}

Allen, D. (2011). Conductive arguments and the Toulmin model: a case study. In Blair and Johnson (pp. 167-190).

Baier, K. (1958). The Moral Point of View. New York: Random House.

(c) David Hitchcock. Informal Logic, Vol. 33, No. 2 (2013), pp. 195-237. 
Bailin, S. and M. Battersby (2010). Reason in the Balance: An Inquiry Approach to Critical Thinking. Toronto: McGraw-Hill Ryerson.

Battersby, M. and S. Bailin (2011). Guidelines for reaching a reasoned judgment. In Blair and Johnson (pp. 145-157).

Blair, J.A. and R.H. Johnson (Eds.) (2011). Conductive Argument: An Overlooked Type of Defeasible Reasoning. London: College Publications.

Ennis, R.H. (2001). Argument appraisal strategy: A comprehensive approach. Informal Logic, 21, 97-140.

Franklin, B. (1956). Mr. Franklin: A Selection from His Personal Letters, edited by W.J. Bell Jr. and L.W. Labaree. New Haven: Yale University Press. Letter of 1772 to Joseph Priestley at http://www.procon.org/view.backgroundresource.php?resourceID=1474; accessed 20130304.

Freeman, J.B. (2011). Evaluating conductive arguments: critical questions in light of the Toulmin model. In Blair and Johnson (pp. 127-144).

Goddu, G.C. (2001). The 'most important and fundamental' distinction in logic. Informal Logic, 22, 1-17.

Govier, T. (1979). Challenge and Response: Carl Wellman. Informal Logic Newsletter, 2 (2), 10-15.

Govier, T. (1980). Assessing arguments: what range of standards? Informal Logic Newsletter, 3 (1), 2-4.

Govier, T. (1985, 1988, 1992, 1997, 2001, 2005, 2010). A Practical Study of Argument, 1st through 7th editions. Belmont, CA: Wadsworth.

Govier, T. (1987a). Two unreceived views about reasoning and argument. In T. Govier, Problems in Argument Analysis and Evaluation (pp. 55-80). Dordrecht: Foris.

Govier, T. (1987b). Beyond induction and deduction. In F.H. van Eemeren et al. (Eds.), Argumentation: Across the Lines of Discipline: Proceedings of the Conference on Argumentation 1986 (pp. 57-64). Dordrecht: Foris.

(C) David Hitchcock. Informal Logic, Vol. 33, No. 2 (2013), pp. 195-237. 


\section{David Hitchcock}

Govier, T. (1999). Reasoning with pros and cons: conductive arguments revisited. In T. Govier, The Philosophy of Argument (pp. 155-180). Newport News, VA: Vale Press.

Govier, T. (2011). Conductive arguments: overview of the symposium. In Blair and Johnson (pp. 262-276).

Hansen, H.V. (2011). Notes on balance-of-considerations arguments. In Blair and Johnson (pp. 30-51).

Hitchcock, D. (1980). Deductive and inductive: types of validity, not types of argument. Informal Logic Newsletter, 2(3), 9-10.

Hitchcock, D. (1981). Deduction, induction and conduction. Informal Logic Newsletter, 3(2), 7-15.

Hitchcock, D. (2002). Sampling scholarly arguments: a test of a theory of good inference (plus "Appendix"). In H.V. Hansen, C.W. Tindale, J.A.Blair, R.H. Johnson and R.C. Pinto (Eds.), Argumentation and Its Applications. Windsor, ON: OSSA. CDROM.

Hitchcock, D. (2009). The culture of spoken arguments. In J. Ritola (Ed.), Argument Cultures: Proceedings of OSSA 09, CD-ROM (pp. 1-19, with Appendix, pp. 1-66), Windsor, ON: OSSA.

Jin, R. (2011). The structure of pro and con arguments: a survey of the theories. In Blair and Johnson (pp. 10-30).

Kauffeld, F. (2011). Ranking considerations and aligning probative obligations. In Blair and Johnson (pp. 158-166).

Naess, A. (1966). Communication and Argument: Elements of Applied Semantics. Totowa, NJ: Bedminster Press.

Oregon, State of (2011). Death with Dignity Act. Oregon Revised Statutes 127.800 to 127.895 . Available at http://www.leg.state.or.us/ors/127.html ; accessed 20130315.

Pinto, R.C. (2011). Weighing evidence in the context of conductive reasoning. In Blair and Johnson (pp. 104-126).

Pollock, J.L. (1995). Cognitive Carpentry: A Blueprint for How to Build a Person. Cambridge, MA: MIT Press.

Pollock, J.L. (2001). Defeasible reasoning with variable degrees of justification. Artificial Intelligence, 133(1), 233-282.

(C) David Hitchcock. Informal Logic, Vol. 33, No. 2 (2013), pp. 195-237. 
Wohlrapp, H. (2008a). Der Begriff des Arguments. Über die Beziehungen zwischen Wissen, Forschung, Glauben, Subjektivität und Vernunft. Würzburg: Königshausen und Neumann.

Wohlrapp, H. (2008b). The pro- and contra- discussion (A critique of Govier's "conductive argument"). Translation of Wohlrapp (2008a), section 6.4 (pp. 316-334).

http://www.frankzenker.de/downloads/Zenker_2008_Translatio n\%20of\%20Wohlrapp\%202008\%20Pro\%20Con\%20Discussion GER_ENGL.pdf; accessed 20130224.

Wohlrapp, W. (2011). Conductive argument: A misleading model for the analysis of pro- and contra- argumentation. In Blair and Johnson (pp. 210-223).

\section{Appendix: Examples of conductive reasoning}

Govier cites the following five passages as examples of conductive argument:

1. There can be no doubt that Emily Bronte casts a vague incestuous aura over the entire plot of Wuthering Heights. Heathcliff marries his lost love's sister-in-law; his wife's son marries her brother's daughter; Cathy's daughter marries her brother's son. An unconsciously incestuous love between the two leading characters would not run counter to the tone of a novel filled with violent and savage scenes, such as the sadistic rubbing of a wrist over a broken window-pane, Cathy's fierce delirium, or the sight of Heathcliff smashing his bloody head against a tree.

(Eric Solomon, "The incest theme in Wuthering Heights," Nineteenth Century Fiction 14 (1951), pp. 82-83; cited by Govier in (1987, p. 71) and (1999, p. 165))

2. That 'this exists' has any meaning in such cases, where, as Mr. Russell would say, we are using 'this' as a 'proper name' for something with which we are acquainted, is, I know, disputed; my view that it has involves, I am bound to admit, the curious 


\section{David Hitchcock}

consequence that 'this exists' when used in this way is always true, and 'this does not exist' always false; and I have little to say in its favor except that it seems to me so plainly true that, in the case of every sense-datum I have, it is logically possible that the sense-datum in question should not have existed - that there should simply have been no such thing.

(G.E. Moore, "Is existence a predicate?" in his Philosophical Papers (London: George Allen and Unwin, 1959), p. 126; cited by Govier in (1987, p. 72)

3. Or we might talk about the "deeper truth" in myths, the more profound lessons Santa can teach. But this is a cheat, for two reasons. It fudges the fact that, on the mundane issue of where presents come from, parents know that what they're saying is false. (Real myth-makers believe their myths.) And it finds a deeper truth where there doesn't seem to be one. In the Santa story, presents come from a stranger who gives gifts to everyone. In reality, presents come from parents who love their kids as individuals and give gifts to express this love. Isn't the reality more worth knowing than the myth?

(Thomas Hurka, cited by Govier as from "a newspaper column" (1997, pp. 447-449; 1999, p. 160))

4. Usually the Santa lie, befitting Christmas, is a white lie. For starters, the lie is only temporary. You tell kids about Santa now, but you'll straighten them out later. The deception isn't forever. And the deception is a mild one. You don't take a falsehood and call it truth; you take a fiction and call it truth-a smaller distortion. This means the loss of the illusion is gentler. When kids are older they don't lose Santa entirely, they just think of him in a different way. Finally, the deception is good for kids. Believing in Santa adds magic and excitement to Christmas; the anticipation is keener, the delight sharper. Parental love is fine and even profound, but a gift from the North Pole is far more exotic.

(C) David Hitchcock. Informal Logic, Vol. 33, No. 2 (2013), pp. 195-237. 
(Thomas Hurka, cited by Govier as from "a newspaper column" (1997, pp. 447-449; 1999, p. 161))

5. (W)hile I like to think of my lifestyle as environmentally conscious, it's actually not all that pure. To get to our house in the country, where the air is cleaner than it is in New York City, my husband and I rack up 350 miles every week. In the summer we pick fresh vegetables and fruit from our own garden, but in the winter we buy them from health food stores that truck them east from organic farms in California. And as a writer, I use papera great deal of paper - and that requires the felling of trees, even when I consciously write on both sides. Unavoidably, I use energy, and using energy makes waste.

(Trebbe Johnson, "Learning to love the waste," cited by Govier without further attribution in (1997, p. 446) ans (1999, pp. 161162))

The following examples were obtained through a Google search using the exact phrase "taking all these factors into account." Among the first 10 search results, some did not use this phrase to introduce a conclusion drawn from premises. Others involved calculation, for example in drawing a conclusion about the size of an increase in the cost of living. Others involved predicting an effect on the basis of causally relevant factors. I quote the remaining three examples of apparently conductive reasoning.

6. The New Jersey Academy of Orthotists and Prosthetists has cancelled its annual conference, scheduled from Nov. 7-9 [2012$\mathrm{DH}]$ in Atlantic City, NJ. Hurricane Sandy hit the Jersey shore and disrupted all essential services in the tri-state area, including NJ, NY and Conn. The New Jersey Academy of Orthotists and Prosthetists (NJAAOP) board and committee discussed the feasibility of going ahead with our conference. The major factors we considered were first, the safety of our members, and second, the lack of information from the hotel regarding the conditions at the hotel and in Atlantic City. The final factor was that

(C) David Hitchcock. Informal Logic, Vol. 33, No. 2 (2013), pp. 195-237. 


\section{David Hitchcock}

most of our attendees have been out of work for assembly and it would be a hardship for them to attempt to attend the conference and miss 3 more days of work. Many members had flooding of their homes and many would not have access to gasoline for the trip. Taking all these factors into account we decided to cancel. We struggled with the decision but in the end we felt it was the right thing to do.

(Carey Glass, President, NJAAOP, "NJAAOP meeting cancelled due to hurricane", November 6, 2012;

http://www.healio.com/orthotics-

prosthetics/education/news/online/\% 7Bba3c371d-1bf6-448b-

82fc-b20e78c36571\%7D/njaaop-meeting-cancelled-due-to-

hurricane ; accessed 20121204 )

7. What to Look for in Voice Recognition Software

We based our review on a few simple criteria, all of which are important in a useful voice recognition program.

\section{Features}

This specialized software has to have the right kind of features. For instance, there needs to be a voice training of some kind to help the computer become familiar with your voice. Other features like customizable commands and accent support also expand the usefulness of the program.

\section{Commands}

The primary function of this software is to let you navigate your computer by voice. That means you must be able to open and close other programs and use the features within them all by voice command.

\section{Dictation}

The second most important function is dictation. This allows you to speak text into Word or other text editor. But the program must be good at recognizing speech in order to accurately transcribe it to text, so dictation is the true test of a good voice recognition program.

\section{Accuracy}

(c) David Hitchcock. Informal Logic, Vol. 33, No. 2 (2013), pp. 195-237. 
We tested the programs in dictation mode and assigned a score to each one based on how many errors they made in transcribing speech. A higher score means a program is better at handling all kinds of words. You can see the full results of our test in the Dictation Test article.

\section{Ease of Use}

Even if a program is excellent at interpreting your voice, it's practically useless if the commands and menus are difficult to use.

By taking all these factors into account, you can accurately choose software that suits you. Depending on your needs, you may find some features are more important than others. For instance, some people might be more interested in commands than dictation capabilities, so be sure to consult the scores for each review category.

("2013 compare best voice recognition software", Top Ten Reviews,

http://voice-recognition-software-review.toptenreviews.com/; accessed 201212 04)

8. Aiming at the measurement, comparison and ranking of all kinds of public dangers, ranging from natural hazards to industrial risks and political perils, the preparation of national risk registers stands out as a novel and increasingly popular Western security practice. This article focuses on these registers and the analytical power politics in which they are complicit. We argue, first, that positing science as an objective determinant of security truth, national risk registers advance a modernist understanding of how knowledge of national dangers can be arrived at, discounting both sovereign and popular authorities; second, that by operationalizing a traditional risk-assessment formula, risk registers make possible seemingly apolitical decisions in security matters, taken on the basis of cost-benefit thinking; and, third, that risk registers' focus on risk 'themes' tiptoes around the definition of referent objects, avoiding overt decisions about the beneficiaries of particular security decisions. Taking all these

(C) David Hitchcock. Informal Logic, Vol. 33, No. 2 (2013), pp. 195-237. 


\section{David Hitchcock}

factors into account, we find that risk registers 'depoliticize' national security debates while transforming national insecurity into something permanent and inevitable.

(Abstract of: Jonas Hagmann and Myriam Dunn Cavelty, "National risk registers: Security scientism and the propagation of permanent insecurity," Security Dialogue (February 2012), 43/1: 79-96; doi: 10.1177/0967010611430436)

A Google search using the phrase "so on balance" turned up no substantive pieces of reasoning; in many cases, nothing preceded the phrase. The phrase "therefore on balance" produced the following four examples of apparent conductive reasoning among the first 10 results:

9. Really difficult to review accurately but, on balance, we loved it and would return.

The hotel has a glorious setting right on the beach which is well groomed and clean. Security is excellent both on the beach and in the hotel 'grounds'. The dive centre combined with the ecological centre are also excellent and have plenty of 'kit' for hire including life jackets. If you like snorkelling, it's easy to get into the water from the beach, the bay is quite shallow \& there is plenty to see including turtles, rays and a host of coral reef fish with some stunning colours. We didn't have children with us but if we had, it would be perfect for them.

The restaurant was excellent. We did not have a bad meal. If we had known beforehand that the quality was as good as it was, we would have purchased a meal deal in advance saving $10 \%$ on bills.

The rooms are kept very clean and the WiFi was a godsend.

After all that, why didn't I give it an 'excellent' rating?

Despite the fact that we would definitely return, the rooms in the hotel block are a bit 'tired' and need refurbishment. The wall $\&$ floor tiles need replacing, the kitchenettes need ripping out and updating, the aircon units need remote controls, the rooms need more power points available for recharging phones \&

(C) David Hitchcock. Informal Logic, Vol. 33, No. 2 (2013), pp. 195-237. 
iPads etc, and the light fittings need fittings. The WiFi signal is not strong enough since it 'drops out' when it shouldn't, the pool is functional but its poolside furniture is tired and needs replacing.

All of the above might be 'picky' but my biggest gripe is that the bay is invaded by snorkel tours with seemingly no regulation. Those arriving by road seem fine but those disgorged into the bay by boats that moor up to await repatriation create a 'too busy' environment. My worry is that if the numbers of visitors are not controlled in some way, the turtles that everyone comes to see will be hounded out of 'their bay'.

Before 09:30 in the morning, the bay is delightful. After 17:00 it is equally delightful. The hotel has it's [sic] own part of the beach that is shaded with palm trees and where loungers are available. You just have to ask. The 'offcomers' are kept at a distance and that allows a really relaxing session on the beach with plenty of space.

Therefore, on balance, we loved it and would return. (Review on tripadvisor.ca of Hotel Akumai Caribe, 24 November 2012, http://www.tripadvisor.ca/ShowUserReviews-g499445d252781-r146088666-Hotel_Akumal_CaribeAkumal_Yucatan_Peninsula.html ; accessed 201212 04)

10. BUSINESSEUROPE would like to express its strong concern regarding the Commission's proposal for "backloading" in the EU Emission Trading Scheme (ETS).

European business supports the central role played by the ETS in the EU climate policy and has called on EU policymakers to start an open debate, involving all stakeholders, on the level of ambition for the EU ETS post 2020. This needs to take place within the context of a comprehensive debate about the future of the EU's energy, climate and industrial policies. An improved coherence among these policies will be crucial for the competitiveness of European industry.

Prior to this longer-term view being developed, short-term measures such as changes to the ETS auctioning regulation to 


\section{David Hitchcock}

"backload" allowances must be avoided as these would interfere with a more constructive discussion on how to achieve a systemic solution. Pre-emptive short-term measures would create a precedent, resulting in greater uncertainty, and could have major repercussions for European business, which is already under strain from the economic crisis.

Therefore, on balance, European business cannot support the proposal for a review of the auction time profile to implement a "backloading" in the EU ETS.

(BUSINESSEUROPE, 3 October 2012,

http://ec.europa.eu/clima/consultations/0016/organisation/busine sseurope_en.pdf ; accessed 201212 04)

11. Two problematic spindle cell sarcomas involving upper jawbones in two adult male patients have been studied by histology, immunohistochemistry, and transmission electron microscopy, and respectively graded as low-grade malignancy and highgrade malignancy. While any single methodological study did not allow confident classification of them into one or other of the classical categories of spindle cell sarcomas (fibrosarcoma versus leiomyosarcoma), the overall contribution from all three methodologies ultimately allowed them to be categorized as sarcomas with myofibroblastic differentiation. Histologically, both tumors had morphological features of an amalgama between neoplastic fibroblasts and smooth muscle cells. Immunohistochemically, both tumors expressed reactivity only for muscle specific actin and alpha smooth muscle actin, in addition to vimentin. Ultrastructurally, both tumors, while showing fibroblast-like cytoplasmic features, had a spurious and imperfectly organized cell surface defying convincing classification into any of specific categories (i.e., both appeared in terms of ultrastructure as poorly differentiated sarcoma, the former with low level of smooth muscle differentiation and possibly the presence of some fibronexus component, the latter with no smooth muscle differentiation but with possible evidence of very rare fibronectin fibril). Therefore, on balance, the most tenable diagnosis

(C) David Hitchcock. Informal Logic, Vol. 33, No. 2 (2013), pp. 195-237. 
seemed to us that of a myofibrosarcoma in both cases. This work is presented considering the fact that myofibrosarcoma currently represents a topical theme of debate, and that this is the first report in medical literature concerning with myofibrosarcomas of the head and neck area in adults.

(Abstract of: Bisceglia M, Tricarico N, Minenna P, Magro G, Pasquinelli G. Myofibrosarcoma of the upper jawbones: a clinicopathologic and ultrastructural study of two cases. Ultrastruct Pathol (2001 Sep-Oct) 25(5):385-97.

http://www.ncbi.nlm.nih.gov/pubmed/11758720; accessed 2012 $1204)$

12. We have consulted with our members in regards to the different options for international criminal health checks and would therefore like to make the following comments with respect to each of the options.

Option 1: Applicant declaration only

The APA [Australian Physiotherapy Association-DH] recognises that this is the least labour intensive option for both AHPRA [Australian Health Practitioner Regulation Agency$\mathrm{DH}]$ and the registrants. However we recognise that the downside to this streamlined approach means that it is unlikely false declarations would be found.

This is not a major concern to the APA as physiotherapy is a low risk profession as evidenced by the data produced by AHPRA in 2010/2011. Only one applicant had a condition or undertaking imposed on their registration as a result of the checks and no physiotherapy registrants had applications refused. Therefore, on balance this is not an unreasonable option for the registration of physiotherapists.

(Australian Physiotherapy Association, Consultation paper on criminal history checks, addressed to the Australian Health Practitioner Regulation Agency, 13 August 2012, available by search at http://www.ahpra.gov.au ; last accessed 201303 18) 